Cahiers d'études africaines

\title{
« Masonic Inborn »
}

Jazz, sociétés initiatiques et afrocentrisme

"Masonic Inborn" : Jazz, Initiation Societies and Afrocentrism

\section{Raphaël Imbert}

\section{(2) OpenEdition}

Journals

Édition électronique

URL : http://journals.openedition.org/etudesafricaines/17909

DOI : 10.4000/etudesafricaines. 17909

ISSN : 1777-5353

Éditeur

Éditions de l'EHESS

Édition imprimée

Date de publication : 5 octobre 2014

Pagination : 999-1026

ISSN : 0008-0055

Référence électronique

Raphaël Imbert, « « Masonic Inborn » », Cahiers d'études africaines [En ligne], 216 | 2014, mis en ligne le 21 janvier 2017, consulté le 30 avril 2019. URL : http://journals.openedition.org/ etudesafricaines/17909; DOI : 10.4000/etudesafricaines.17909 


\section{«Masonic Inborn »}

\section{Jazz, sociétés initiatiques et afrocentrisme}

"Music Is a Healing Force of the Universe»: le son de la lutte

Nous sommes en 1969 à New York, pour un enregistrement qui est tout autant historique qu'unique en son genre. C'est l'une des dernières manifestations discographiques de l'immense Albert Ayler, artiste saxophoniste aussi influent que maudit. Il succombera mystérieusement quelque temps après, retrouvé noyé dans l'Hudson River après un mois de disparition. Son statut d'artiste maudit n'en sera que renforcé.

Mais pour l'heure, accompagné de son épouse et chanteuse Marie Maria Parks, qui cosigne les compositions, Albert Ayler est présent dans ce studio pour démontrer que la «musique est la force salvatrice de l'univers » ${ }^{1}$. Pour un des moments les plus intenses et étranges de l'histoire du jazz, il empoigne une cornemuse et entame une longue improvisation free d'une douzaine de minutes, avec ses compagnons musiciens, parmi lesquels un Bobby Few en grande forme ${ }^{2}$. Ce morceau de bravoure pour le moins singulier - la cornemuse n'est pas à proprement parler un instrument familier du jazz, ni du saxophoniste! - sera baptisé « Masonic Inborn » par son auteur, ce que l'on peut traduire par «intrinsèquement maçonnique » ou « maçonniquement né ».

Il reste désormais pour nous à constater l'évidence. Personne n'a cru bon de relever, à l'époque comme maintenant, l'incongruité d'un titre qui demeure, pour le moment, la seule référence explicite à l'ordre maçonnique dans l'histoire du jazz, pas plus que l'utilisation d'un instrument singulier dans ce contexte, emblème d'une culture écossaise et celtique qui paraît bien lointaine de l'afro-américanité supposée intrinsèque à la musique d'Ayler. Pourtant, les connaisseurs d'histoire maçonnique noteront immédiatement la pertinence d'un titre maçonnique avec cette référence explicite à l'Écosse, terre natale mythique de la franc-maçonnerie européenne. De fait, à partir de ce constat, nous pourrons nous interroger sur la pertinence d'un lien

1. Music is the Healing Force of the Universe, titre de l'album paru chez Impulse. Albert Ayler, Music Is The Healing Force Of The Universe, Impulse !, AS 9191.

2. Il y ajoutera aussi, en re-recording, d'autres pistes de cornemuses et d'ocarina. 
supposé entre musique jazzistique, orale par définition, et un fait maçonnique afro-américain méconnu, mais pourtant bien identifié par les recherches contemporaines, en France, de Cécile Révauger (2014) et, aux États-Unis, des membres de la Phylaxis Society ${ }^{3}$, de Craig Steven Wilder (2001), de Corey B. Walker (2008), de Peter P. Hinks et Stephen Kantrowitz (2013).

Mais plus encore, ce qui est passionnant de constater en l'occurrence, c'est cette réelle conjonction entre une pensée spirituelle, politique et philosophique parfaitement constituée et la création d'un langage musical inédit, qui converge vers un imaginaire et une identité afro-américaine nouvelle, que l'on identifiera comme afrocentriste, tout au moins préfigurant clairement l'afrocentrisme politique triomphant de la fin du $\mathrm{Xx}^{\mathrm{e}}$ siècle. Ainsi, jazz, franc-maçonnerie noire américaine et afrocentrisme forment visiblement un ensemble politique, spirituel et philosophique homogène, issu de l'histoire sociale, religieuse et initiatique du peuple afro-américain. Le jazz représente une identité musicale nouvelle, et la franc-maçonnerie noire américaine offre l'outil symbolique et politique idéal pour contribuer à faire émerger cet afrocentrisme intellectuel, esthétique et idéologique dont ils ont porté la gestation. Le jazz et la franc-maçonnerie ont été souvent vus comme des épiphénomènes de la lutte des droits civiques et en tout état de cause comme peu engagés dans les débats intellectuels et politiques qui en sont le corollaire, l'un trop lié au business de l'entertainement, l'autre trop embourgeoisée et singeant une institution après tout européenne. Pourtant, nous constaterons que l'un et l'autre, loin d'être les suiveurs ou les ignorants d'une lutte qui les dépasse, ont été au contraire les précurseurs et les créateurs d'une pensée qui allait être appelée à un succès évident.

Le Jazz et le fait maçonnique ${ }^{4}$

Interrogeons-nous maintenant sur la réalité du fait maçonnique dans l'histoire du jazz. Après tout, elle semble pour le moins ténue, puisqu'absente de l'historiographie académique de cette musique. On peut donc sans problème

3. Société de recherche sur la Prince Hall Masonry, dont le site internet regroupe de nombreux essais, dont certains écrits de Joseph A. Walkes, <http://www. thephylaxis.org/>.

4. Pour une étude complète du fait maçonnique, de son histoire et de son implication sociale et symbolique dans l'histoire du jazz, voir IMBERT (2014). J'y étudie précisément les liens qui existent depuis la naissance du jazz avec le fait initiatique et maçonnique et comment s'opère un paradoxe fondateur entre le nombre de musiciens francs-maçons et l'absence de musique y faisant spécifiquement référence, ainsi que la manière dont cette occurrence influence l'imaginaire spirituel et politique des artistes, maçons ou pas. Toutes précisions historiques et scientifiques supplémentaires qui seraient nécessaires à la compréhension du présent article sont à trouver dans cet ouvrage, ainsi que dans un article (ibid. 2011), plus centré sur l'aspect biographique. 
considérer le jazz historiquement, sociologiquement et plus encore musicologiquement sans évoquer l'appartenance maçonnique avérée ou supposée de quelques-uns de ses acteurs. Après tout, ce fait maçonnique ne se nourrit-il pas généralement de fantasmes, de mythologies et d'approximations qui voient trop souvent de fervents illuminés interpréter n'importe quel signe un tant soit peu étrange ou nébuleux comme autant de démonstration d'un ésotérisme qui gouverne le monde? Le jazz n'échappe pas à la règle, puisque, d'après certains $^{5}$, il est maçonnique par essence, ternaire, mystique et symbolique. Loin de ce genre de spéculations, il semble pourtant judicieux de se pencher sur un nombre finalement important de documents qui démontrent la pertinence de l'appartenance maçonnique dans le milieu du jazz, particulièrement dans la première moitié $\mathrm{du} \mathrm{Xx}^{\mathrm{e}}$ siècle. Parmi tant d'autres témoignages, le contrebassiste Milt Hinton semble ainsi résumer, dans son autobiographie, l'intérêt que représente l'initiation maçonnique pour le musicien, en l'occurrence celui qui appartient à l'orchestre célébrissime de Cab Calloway :

« Beaucoup de musiciens établis de l'orchestre, à commencer par moi, étaient francsmaçons. Cab (Calloway Ndt) l'était aussi. La plupart d'entre nous ont été initiés à la Pionner Lodge $\mathrm{n}^{\circ} 1$, Prince Hall, à St Paul, et à chaque fois que nous jouions dans cette ville, nous essayions de passer du temps dans la loge. Si quelqu'un dans l'orchestre se montrait digne et exprimait le désir de nous rejoindre, l'un d'entre nous le recommandait et essayait d'organiser l'initiation. Mais nous étions assez nombreux dans l'orchestre pour organiser, en tournée, nos propres tenues. Parfois, entre les sets, back-stage, nous avions de courtes réunions et des lectures dirigées. Nous passions toujours du temps avec les gars qui étaient nouvellement initiés, essayant de leur enseigner le réel sens de la Maçonnerie, et comment cela pouvait les aider dans leur vie de tous les jours.

Être Maçon est une chose sacrée. Il y a beaucoup de secrets à ce propos, c'est pourquoi les gens ne parlent pas de ce qui s'y passe. C'est vraiment un système moral basé sur la Bible. Il y a beaucoup de signes et de symboles que seuls les Maçons connaissent, et si tu n'y appartiens pas, c'est difficile à comprendre.

J'ai toujours pensé que le problème majeur avec la Maçonnerie c'est son rapport à la race. Il ne devrait pas y avoir de système noir et blanc séparés, pourtant c'est le cas. Cela semble contredire complètement la philosophie de l'organisation. Mais depuis que je suis Maçon, j'ai été capable de me faire mon opinion sur le problème racial grâce à ce cadre. Ça n'a jamais été un problème pour moi, j'ai essayé de garder cela à un niveau normal. Et je n'ai jamais senti que j'avais à accepter quelqu'un juste parce qu'il est Maçon. Si une personne ne se conduit pas de manière adéquate - s'il ne vit pas selon les règles auxquelles il a juré d'obéir — j'estime que je n'ai juste rien à faire avec lui » (Hinton, Berger \& Maxson 2008: 111, ma traduction).

Milt Hinton, remarquable photographe par ailleurs, accompagne ce texte d'une photographie qui le montre avec Cab Calloway en tablier maçonnique.

5. Notons au passage les efforts importants d'un franc-maçon turc dans son texte «Jazz and Freemasonry » pour prouver avec de nombreuses tentatives de démonstrations numérologiques, mathématiques et analogiques, le caractère intrinsèquement maçonnique du jazz : <http://web.mit.edu/dryfoo/masonry/Essays/jazzmasonry.html>. 
L'initiation de ce dernier sera même annoncée dans la presse ${ }^{6}$. De nombreuses autres photographies du même type existent, ainsi que de similaires témoignages biographiques et autobiographiques, qui démontrent que le sujet mérite d'être étudié. Dans le cadre de mes recherches sur le spirituel dans le jazz, j'ai particulièrement focalisé mon attention sur ce fait maçonnique, pour ce qu'il représente de nouveauté scientifique, et pour la manière dont il éclaire les raisons d'une amnésie médiatique, académique et historique sur le sujet du spirituel en général, et maçonnique en particulier. J'ai ainsi pu analyser cette amnésie et ses causes qui relèvent de la manipulation biographique subie par de nombreux jazzmen à travers la collection d'auteurs biographes plus ou moins scrupuleux (Imbert 2011) ${ }^{7}$. Dans un ouvrage récent sur le fait spirituel en général dans le jazz (ibid. 2014), j'expose plus précisément le fruit de ces recherches pour mieux souligner l'importance qu'elle revêt dans notre compréhension anthropologique et sociétale du jazz. J'y ai établi une liste circonstanciée de francs-maçons jazzmen actifs dont seuls quelques-uns des noms les plus connus permettront de comprendre l'impact de ce fait méconnu : Duke Ellington, Count Basie, Lionel Hampton, Nat « King » Cole, Cab Calloway, Milt Hinton, Kenny Clarke, Oscar Peterson, Luis Russell, Bunk Johnson, George Lewis (clarinette), Eubie Blake, W. C. Handy, Ben Webster, Johnny Hodges, Garvin Bushell, Oscar « Papa » Celestin, Earl Hines, Bill «Bojangles » Robinson (danseur), Harry Dial ${ }^{8}$, Jimmy Rushing, Will Vodery, Cozy Cole, etc.

Et aussi les bluesmen: T-Bone Walker, Sammy Price, Memphis Slim, Howlin' Wolf, Fred McDowell, Son House, Champion Jack Dupree'. Une liste non exhaustive édifiante, un véritable Who's Who du jazz historique qui éclaire même d'une lumière nouvelle la naissance du langage jazzistique à la Nouvelle Orléans au début du Xxe siècle. Car ce sont les clubs, sociétés fraternelles et loges maçonniques, pléthoriques dans cette ville avide de sociabilité, de «caste» et de syncrétisme (avec une présence unique de vaudou, de catholicisme et de cultures initiatiques européennes, créoles et africaines) qui organisent les très nombreux défilés et parades funéraires si typiques de la vie sociale et musicale de la Crescent City (Stearns 1956; Imbert 2011, 2014). Les temples maçonniques sont aussi les lieux privilégiés des joutes musicales et des grands événements culturels de la ville, étant moins ségrégués et plus abordables que les autres lieux mondains. Ici, le grand Buddy Bolden, considéré comme le premier jazzman de l'histoire,

6. Twin City Herald, 24 juin 1934.

7. Je remercie chaleureusement Jean Jamin pour son aide et ses conseils avisés.

8. Dans son autobiographie, il parle de sa loge de New York (Hiram Lodge \#4) et de son activité musicale, qu'il nomme «la loge des musiciens» tant ils y sont nombreux, pour certains parmi les plus célèbres de l'époque.

9. La liste, ici non exhaustive, est plus complète dans R. IMBERT $(2011,2014)$. Les références multiples mais circonstanciées, essentiellement issues de biographies et d'autobiographies, mais aussi de documents maçonniques et journalistiques, y sont précisées. 
vient affronter ses concurrents et démontrer une maîtrise originale de l'improvisation, dans un langage nouveau qui est appelé à envahir le monde (Marquis 1989). Le National Park of History of Jazz de New Orleans ne recense pas moins d'une dizaine de temples maçonniques ou fraternels comme landmarks (monuments historiques) de la naissance du jazz (National Park Service 1993). En développant cette recherche à l'aire américaine dans son ensemble, on peut rapidement constater que le temple est un lieu privilégié de concerts et de rencontres musicales, bien au-delà de la ville louisianaise. Chicago, qui a dès les années 1920 recueilli de nombreux musiciens louisianais, témoigne aussi de cette culture musicale initiatique et symbolique, depuis Earl Hines, inventeur du piano jazz moderne, jusqu'aux expérimentations du collectif AACM et de l'Arkestra de Sun Ra, profondément nourri d'ésotérisme et de mysticisme, nous y reviendrons.

Dans cette perspective, j'ai donc démontré dans mes précédents écrits l'importance inédite de cette relation méconnue entre jazz et appartenance maçonnique, qui bute sans aucun doute sur l'absence quasi totale de musique dite «maçonnique » (selon la formule, il n'y a pas de «Flûte Enchantée » du jazz !) mais ne cache pas une nouvelle vision de l'implication spirituelle, politique et intellectuelle du jazzman vis-à-vis de son époque, et selon le prisme de l'influence maçonnique et de l'appartenance ou non à l'ordre maçonnique. Le militantisme actif ou passif du musicien s'éclaire alors d'une manière originale quant à l'évidente corrélation qui apparaît entre cette appartenance et l'émergence d'une pensée pré-afrocentrique, du moins d'une pensée qui dispose dès le début du XIX siècle les premiers éléments d'un imaginaire qui portera ses fruits près d'un siècle et demi plus tard : égyptocentrisme, ésotérisme afro-mythologique, éthiopianisme, afrofuturisme, symbolisme, révisionnisme et relecture historique, réappropriation des mythes fondateurs occidentaux, fierté noire, nationalisme noir. C'est cette émergence déterminante qu'il convient ici d'étudier plus précisément, comme une préhistoire culturelle et intellectuelle de l'afrocentricité militante qui triomphera officiellement bien plus tard, à la suite des réflexions afrocentriques de George G. M. James (1954) et, dans l'espace francophone, de Cheikh Anta Diop (1954), ainsi que des ouvrages de Martin Bernal (1987), de Molefi Kete Asante (1980) et Théophile Obenga (1993) ${ }^{10}$.

10. Nous comprenons donc ici le terme «afrocentrisme » comme le courant de pensée qui stipule qu'une occultation volontaire académique et «eurocentrée » a nié l'apport africain à la dynamique de civilisation de l'humanité depuis l'Antiquité jusqu'à nos jours. Il s'agit alors de faire œuvre de justice, de « recentrer » et de révéler cet apport dans l'Histoire, dans une logique «contributionniste » (GUEDJ 2009 : 14) en particulier en observant une primauté supposément africaine dans les origines de la civilisation occidentale et savante (Égypte). L' « afrocentricité » chère à Asante répond quant à elle, plus récemment, à un effort de "scientificité » face aux nombreuses critiques que n'a pas manqué de provoquer la pensée afrocentrique, en tâchant de s'éloigner d'un « complotisme » trop primaire tout en continuant à assumer un projet de recentrage de l'Histoire, voire d' "Art de Vivre » afrocentré (ibid.). Évoquons au passage les «théories de la Mélanine » 


\section{"The Song of Underground Railroad». Les racines d'une nouvelle conscience noire}

Au-delà de la Louisiane et du premier jazz, ce jazzman noir ${ }^{11}$ du Who's Who maçonnique œuvre, en tant que musicien et en tant que « frère », dans les temples maçonniques dédiés à une tradition initiatique spécifiquement afro-américaine. Cette Prince Hall Masonry, du nom du fondateur de la première African Lodge de Boston en 1784 - lui-même fut initié en 1775 par des militaires irlandais avec une quinzaine d'autres « Africains » - naît du refus des francs-maçons blancs d'initier et d'accepter les Noirs dans leur temple. Première institution noire constituée avant même les Églises ${ }^{12}$, implantant en pleine révolution américaine l'idée d'une autonomie politique, sociale et spirituelle afro-américaine, elle sera appelée à se développer très rapidement. Elle prendra la tête d'une forme active mais quasi clandestine d'émancipation, créant parmi les premières écoles, les premières universités, les premiers journaux, les premières associations abolitionnistes noires, contribuant à l'édification d'une petite bourgeoisie noire sur le territoire, minoritaire mais résistante (Walker 2008 ; Hinks \& Kantrowitz 2013 ; Révauger 2014).

Elle sera également l'une des contributrices à l'organisation clandestine que fut l' «Underground Railroad». Ce « chemin de fer souterrain » était un réseau étendu d'abolitionnistes blancs et noirs, militants, anciens esclaves, membres influents de la société civile, de l'Église, d'organisations sociales, constitué pour permettre l'exfiltration d'esclaves fugitifs, le plus souvent vers le Canada. Parmi les grandes figures qui ont permis à ce réseau d'exister, certaines comme Lewis Hayden (Grande Maître de la Grande Loge Prince Hall du Massachusetts), Josiah Henson (l'inspirateur de Harriet Stowe pour La Case de l'Oncle Tom) ou James Walker Hood (Grande Maître de

qui représentent les aboutissements les plus contemporains, radicaux et essentialistes de cette pensée. Nous parlons donc ici de «pré-afrocentrisme » pour désigner ce qui peut, dans le cadre de notre étude, être identifié comme étant les racines anciennes (du XVIII ${ }^{\mathrm{e}}$ siècle à la Seconde Guerre mondiale) des différents courants de la pensée afrocentrique (qui eux émergeront essentiellement après guerre) : éthiopianisme, «egyptomania », références abyssiniennes, nationalisme noir, retour à l'Afrique, ésotérisme noir, islam noir, Black Beauty, symbolisme maçonnique noir, théologie noire, églises noires, afro-futurisme (Sun Ra), etc. Nous renvoyons également à la lecture des travaux de P. GuEDJ (2003, 2004, 2009) et de W. J. Moses (1998) pour une étude critique constructive des afrocentrismes américains, ainsi qu'à C. CHIVALLON (2004) pour une mise en situation anthropologique de ces afrocentrismes vis-à-vis de l'ensemble des mouvements issus de l'histoire diasporique.

11. N'oublions pas au passage les très nombreux « frères » blancs du jazz et de l'entertainment américain : Paul Whiteman, Al Jolson, Glenn Miller, Irving Berlin, Joe Morello, etc.

12. Je montre dans Jazz Supreme (IMBERT 2014) le rôle déterminant que les loges de Prince Hall ont eu dans la création des premières Églises méthodistes noires. Prince Hall lui-même devint un prédicateur apprécié de l'AMEC (African Methodist Episcopal Church), et Richard Allen, premier évêque de cette Église, un membre actif de l'African Lodge. 
la Grande Loge Prince Hall de Caroline du Nord, mais aussi évêque de l'African Methodist Episcopal Zion Church) nous rappelle le rôle déterminant que l'ordre maçonnique a eu sur le réseau. Une littérature importante semble même défendre l'idée que la symbolique maçonnique permettait l'élaboration d'un langage secret que seuls les fugitifs et les organisateurs du réseau pouvaient connaître, au nez et à la barbe des esclavagistes. Une mythologie du langage du quilt afro-américain naît notamment sous la plume de Jacqueline Tobin (Tobin \& Dobard 1999), qui avance la fonction secrète des tissus élaborés par les esclaves pour mieux indiquer la marche à suivre pour le fugitif, comme une cartographie ésotérique sous influence maçonnique. Un pendant visuel et symbolique du supposé message codé des Negro Spiritual. Si cette littérature ne repose sur rien de concret, elle révèle la place fantasmagorique dans l'imaginaire commun de la maçonnerie dans la lutte contre l'esclavage, qui, elle, est bien réelle ${ }^{13}$.

La franc-maçonnerie noire américaine de Prince Hall, en tant qu'institutionphare de la jeune émancipation masculine afro-américaine, sera aussi dès sa création à l'initiative de toutes les tendances de la lutte pour les droits civiques. Prince Hall lui-même, véritable précurseur des grands leaders de la cause, sera à l'origine d'un nombre conséquent d'actions contre l'esclavage, pour l'éducation des enfants et des hommes libres, pour le retour à l'Afrique, dès la fin du XVIII siècle (Révauger 2014). Plus encore, alors qu'elle fut considérée comme une institution conservatrice et attentiste, la Prince Hall Masonry inspirera parmi les plus radicaux et révolutionnaires des activistes abolitionnistes, prolongeant le travail de Prince Hall (1797 dans Newman et al. 2000) qui appelait ses frères à ne pas oublier Haïti et l'exemplarité de sa révolution. Le plus significatif à ce sujet demeure David Walker, auteur en 1829 du fameux Appeal to the Colored Citizens of the World. Profondément marqué par la tentative de révolte avortée en 1822 de Denmark Vesey, l'un de ses coreligionnaires méthodistes de Charleston, David Walker appelle dans ce texte fondateur les citoyens noirs du pays et d'ailleurs à conquérir leur liberté par eux-mêmes, par la force si besoin. Citant abondamment Richard Allen, le fondateur de l'Église méthodiste noire et compagnon de route de Prince Hall, David Walker lance un vibrant manifeste religieux et révolutionnaire qui théorise en quelque sorte les nombreuses tentatives révolutionnaires de l'époque, de Gabriel Prosser à Nat Turner, et préfigure l'idée d'un nationalisme noir (Asukile 1999) et d'une lutte panafricaine de la diaspora. Mais le texte met aussi l'accent sur l'éducation des masses noires comme outil primordial de la liberté et de l'émancipation. En tant que membre actif de l'Église méthodiste, des loges de Prince Hall, de la Massachusetts General Colored Association (organisation antiesclavagiste de Boston créée en 1826, et fondée par de nombreux maçons

13. Même si, par ailleurs, il y a aussi de nombreux maçons parmi les esclavagistes. La loge de recherche La Pérouse l'a parfaitement démontré dans son dictionnaire des marins francs-maçons. Site de la respectable loge La Pérouse, <http://www. rllaperouse.org/>. 
de Prince Hall et méthodistes de la ville, comme Thomas Dalton), et en tant que chroniqueur au Freedom's Journal de New York, premier journal abolitionniste créé par des Afro-Américains, David Walker illustre parfaitement ce paysage culturel qui œuvre pour l'émancipation et qui s'agence selon trois organisations autonomes mais dépendantes : l'organisation laïque et politique (MGCA ; Freedom's Journal), l'organisation initiatique et fraternelle (Masonry) et l'organisation religieuse (Église méthodiste). Ce triptyque qui permet d'abord à une infime minorité de Noirs libres de se construire une identité propre, et, ce faisant, de transformer leur statut et leur situation d'esclave et de descendant d'esclave malgré la domination blanche, est appelé a devenir au fil des années le schéma conducteur de la lutte pour les droits civiques. Malgré les efforts couronnés d'un certain succès des Black Panthers ou de Nation of Islam pour contester à la Prince Hall Masonry (Muhammad 2008) toute légitimité dans la lutte des classes et des races, nous pouvons voir dans le destin d'un Jesse Jackson, pasteur, franc-maçon de Prince Hall, politicien, activiste, une continuité contemporaine de l'œuvre et l'action triptyque commencée par Prince Hall, David Walker et Richard Allen. Les maçons de Prince Hall ne s'y tromperont pas, et auront toujours à cœur de valoriser leur place dans l'histoire de cette lutte, en honorant de grands leaders et activistes par un acte initiatique original, l'initiation at sight, qui consiste à gratifier une personnalité d'une appartenance maçonnique honoris causa, sans cérémonie d'initiation, au simple regard de son œuvre et de son action. Booker T. Washington, W. E. B. Du Bois, Paul Robeson (et après son assassinat, de manière posthume Martin Luther King, ce qui a contribué à brouiller les pistes sur son appartenance supposée à la maçonnerie) ont ainsi accepté cette appartenance honorifique, d'autant mieux qu'ils savaient eux-mêmes ce qu'ils devaient à cette institution fondatrice (Révauger 2014). Nous voyons ainsi que, par cette action, les maçons de Prince Hall honorent pareillement les tenants d'une ligne de compromis et de discrétion (Washington) que les tenants d'une ligne plus révolutionnaire (Du Bois, et Paul Robeson, tous deux communistes notoires).

Mais la personnalité maçonnique qui nous intéresse le plus dans le cadre de notre essai est sans conteste Martin R. Delany (1812-1885). Médecin, militant abolitionniste, écrivain, journaliste, essayiste prolifique, sa forte personnalité aura ainsi marqué son temps et ses contemporains, devenant, chose unique à l'époque, officier major de l'armée américaine nordiste et ainsi le plus haut gradé afro-américain de la guerre de Sécession. Influencé par le révérend Lewis Woodson ${ }^{14}$ qu'il côtoya dans sa jeunesse, il deviendra

14. Pasteur de l'African Methodist Church, il sera connu pour ses chroniques dans le journal Colored American signées sous le pseudonyme Augustine, du nom du saint catholique «africain». Ses appels à l'indépendance intellectuelle et politique des Noirs, par la création d'institutions totalement autonomes du pouvoir blanc, feront dire à l'historien F. Miller (1971) qu'il était le «Father of Black Nationalism». 
sans doute l'activiste et intellectuel afro-américain le plus virulent et le plus original de l'époque. Proche de Frederick Douglass, avec qui il édite le journal abolitionniste North Star, il convient de l'impossibilité de faire évoluer favorablement la situation des Noirs aux États-Unis. Il milite rapidement pour un retour à l'Afrique qu'il théorise en 1852 dans The Condition, Elevation, Emigration, And Destiny Of The Colored People of The United States (Delany 2003) et qu'il préparera concrètement en 1859 par une longue expédition sur la côte est de l'Afrique, sans pour autant parvenir à ses fins (ibid.). Ses théories sur la franc-maçonnerie et sur l'ethnologie sont particulièrement intéressantes à observer. Membre actif de la franc-maçonnerie, il est évidemment scandalisé par la ségrégation qui règne aux États-Unis jusque dans le contexte initiatique et fraternel. Il publie en 1852 un texte précurseur, The Origin and Objects of Ancient Freemasonry, dans lequel il affirme la légitimité de la maçonnerie noire américaine. Pour lui, aucun doute, la franc-maçonnerie plonge ses racines dans l'Afrique : «Je pense que tous les orateurs et écrivains de bon sens admettent et reconnaissent que le monde est redevable à l'Afrique pour sa connaissance des mystères de la franc-maçonnerie ancienne » (Révauger 2014: 90). Il ajoute : «Dois-je hésiter à dire au monde entier que, en ce qui concerne la francmaçonnerie, le mot "Eureka" fut prononcé pour la première fois en Afrique ? Mais allons bon, je viens de révéler le secret maçonnique et je dois m’arrêter là » (ibid. : 63).

La préséance grecque dans la chronologie des civilisations et des mystères ésotériques est ainsi réadaptée, voire franchement contestée. La noble et ancienne institution maçonnique n'est plus seulement une société européenne de bâtisseurs, héritière du temps des cathédrales et de la Haute Antiquité européenne. Elle doit son nom et sa création à la sagesse commune de l'Égypte et de l'Éthiopie, et aucun Blanc ne peut alors se prévaloir d'une légitimité accrue sur elle vis-à-vis de ses frères noirs. Un credo qui revisite entièrement l'histoire officielle selon un point de vue que l'on peut sans problème placer dans une perspective pré-afrocentrique. Les « kemetistes » ${ }^{15}$ actuels n'en penseraient pas moins. Une littérature afrocentrique contemporaine reprend désormais à son compte l'hypothèse de l'origine africaine de la maçonnerie, voire de l'usurpation de la maçonnerie européenne vis-à-vis de la véritable maçonnerie noire ${ }^{16}$.

15. Nous entendons, au-delà de l'anecdote, par kemetistes les représentants des différents mouvements néo-religieux, essentiellement afro-américains, qui tentent de renouer avec les cultes égyptiens sous une acceptation justement afrocentrique. Au-delà de ces mouvements souvent disparates, le mot « kemet » peut s'identifier comme un véritable slogan pour de nombreux afrocentristes et nationalistes noirs contemporains. Artistiquement, le terme est de plus en plus revendiqué, comme dans le nom d'un remarquable groupe actuel, The Sons of Kemet.

16. Voir à ce sujet, avec la distance nécessaire: GrEMILLION (2005), MoORE (2008) ou les DVD qu'Ashra Kwesi diffuse sur son site <http:www.kemetnu.com> tel African Origins of Western Freemasonry. 
Ainsi, pour Delany, «l'Afrique a produit l'Égypte, l'Égypte a produit la connaissance maçonnique, la connaissance maçonnique a produit le monde », comme le résume parfaitement l'historien Scott Trafton (2004). Il théorisera, près d'un siècle avant l'émergence d'un afrocentrisme officiel et intellectuel, le lien vigoureux entre Égypte ancienne et Éthiopie, civilisations noires primordiales, dans un autre ouvrage important: Principia of Ethnology (Delany 1879) où il tentera même de proposer sa propre vision des hiéroglyphes, contre celle, trop « eurocentrée » de Champollion. Martin R. Delany peut être vu à juste titre comme l'un des fondateurs du nationalisme noir, mais également comme l'un des premiers vulgarisateurs d'une pensée spécifiquement afrocentriste. Scott Trafton (2004) étudie la place de la question raciale dans l'émergence et l'essor d'une égyptomanie américaine, blanche et noire. La même passion pour l'Égypte ancienne repose sur des fondements idéologiques radicalement différents que l'on soit Blanc ou Noir. Pour les uns, la mythologie et l'archéologie égyptiennes justifient les récits bibliques et la réalité de la supériorité occidentale. Pour les autres, l'Égypte est, de fait, la première grande civilisation de l'histoire, et elle est africaine. Il y a là déjà un point commun avec la franc-maçonnerie qui, nous l'avons vu, légitime les thèses esclavagistes et ségrégationnistes de nombreux frères blancs, en même temps que la cause abolitionniste des autres, ainsi qu'une vision fièrement africanisée du mythe maçonnique par les frères de Prince Hall. Mais plus particulièrement, Scott Trafton démontre aussi l'importance de la culture maçonnique dans l'édification de cette égyptomanie américaine ambivalente. Martin R. Delany a ainsi résumé une vision afrocentriste de la civilisation égyptienne et du mythe de l'Éthiopie comme terre-mère originelle, qui était déjà à l'œuvre dans l'imaginaire des maçons de Prince Hall.

L'appropriation des mythes maçonniques par les francs-maçons noirs dès la fin $\mathrm{du} X \mathrm{XVIII}$ e siècle, comme la relecture des textes bibliques par les premiers méthodistes noirs, sont les maîtres d'œuvres initiatiques et religieux (nous pourrions dire ésotériques et exotériques) d'une nouvelle vision du monde qui se place selon l'expérience afro-américaine émergente, pour l'édification d'une identité spécifique. La Bible, particulièrement les psaumes et l'Ancien Testament, sont relus à la lumière d'une tradition maçonnique qui met en valeur des personnages plus orientaux, plus africains, comme Noé, Salomon, la Reine de Sabah, et Jethro, le beau-père de Moïse. Dans sa fameuse adresse aux francs-maçons de 1797, Prince Hall voit en Jethro un sage, «un Éthiopien », précurseur de la connaissance maçonnique. Sa parfaite culture biblique et son activisme maçonnique font de Prince Hall, premier franc-maçon noir américain, un penseur original qui oriente son point de vue vers l'Afrique, vers l'Éthiopie. Après avoir usé des métaphores bibliques pour mieux dénoncer l'esclavage et les crimes odieux qu'il génère, il appelle ses frères à la mobilisation, comme une obligation maçonnique :

«Mes frères, souvenons-nous de ce qu'était une sombre journée pour nos frères africains il y a six ans, dans les Antilles françaises. Rien que le claquement de 
fouet du matin au soir ; pendus, roués de coups, brûlés, et toutes sortes de tortures infligées à ces gens malheureux, rien que pour satisfaire l'orgueil, la luxure et la cruauté de leur maître : mais béni soit Dieu, la situation change; ils confessent maintenant que Dieu n'a aucun respect pour eux et donc les reçoivent comme leurs amis, et les traitent comme des frères. Ainsi l'Éthiopie commence à étendre sa main, depuis le bourbier de l'esclavage jusqu'à la liberté et l'égalité » (Newman et al. $2000: 47$, ma traduction).

Au-delà de l'évidence d'une utopie propre à la culture maçonnique et biblique de Prince Hall, qui mettra sans aucun doute plus de temps à se réaliser qu'il ne l'imagine, nous voyons apparaître ici le fruit d'une relecture des textes sacrés et mythologiques. «L'Éthiopie qui étend sa main » fait référence à l'évangile de Matthieu (12:13) lorsque Jésus guérit un homme en plein sabbat, contre l'avis des pharisiens. Il fait référence également au fameux psaume 68 (31) : "Princes shall come out of Egypt; Ethiopia shall soon stretch out her hands unto God» selon la Bible de King James. Le franc-maçon américain est, contrairement à l'image française et européenne de la maçonnerie, profondément pétri de culture biblique. Le franc-maçon noir américain est logé à la même enseigne mais en y ajoutant, dès Prince Hall lui-même, une relecture particulière, plus afrocentrée. Martin Delany (1879) utilisera ce psaume pour conclure son essai Principia of Ethnology, marquant ainsi les débuts d'un éthiopianisme qui sera triomphant quelques décennies plus tard. Ainsi, les textes bibliques et maçonniques justifient pour les maçons de Prince Hall une nouvelle vision afrocentrée du monde, avec l'Égypte et l'Éthiopie comme fondations mythiques et grandioses. Une vision qui aura des conséquences au-delà des États-Unis, et vers une île qui aura elle aussi une pérennité musicale et religieuse efficace : la Jamaïque. L'un des créateurs du rastafarisme, Joseph Nathaniel Hibbert, est initié en 1924 au Costa Rica à l'Ancient Mystic Order of Ethiopia, organisation maçonnique liée à la Prince Hall Masonry. À son retour en Jamaïque, Hibbert s'inspirera de son expérience initiatique pour orienter le culte de l'Église copte éthiopienne, qu'il créée. Et pour y implanter en 1941, avec Leonard Howell et Archibald Dunkley, une branche maçonne «mystique et éthiopienne », prêchant le règne sacré d'Haile Selassie et mêlant culture biblique, logique initiatique et mythologie salomonique (Smith et al. 1967). David Williams Spencer (1999), dans Dread Jesus, pousse l'analogie maçonnique encore plus loin : le mot rastafarien «Jah» («Dieu») proviendrait du nom maçonnique de Dieu «Jahbulon », présent dans le rituel maçonnique du Royal Arch, populaire en Amérique du Nord !

Nous ne connaissons pas l'influence directe de la maçonnerie sur les musiciens pionniers du reggae rastafarien, même si une étude semble s'imposer. Il en est de même pour d'autres territoires des Caraïbes, qui mêlent conjointement culture maçonnique et musicale, comme à Haïti, ou Cuba (où la maçonnerie, héritière de la révolution bolivarienne, continuera de prospérer sous Castro). 
Mais nous connaissons désormais l'importance de la maçonnerie de Prince Hall chez les musiciens de jazz afro-américains. Il convient donc d'éprouver ce fait maçonnique musical original à ce pré-afrocentrisme que nous venons d'étudier, pour constater la manière dont les artistes se sont inscrits dans cette nouvelle vision du monde. Nous constaterons alors l'évidence : la glorification de la beauté de la culture noire par les francs-maçons de Prince Hall trouve une parfaite résonance musicale avec le jazz.

\section{Africa Brass, Coltrane et I'Afrique}

John Coltrane signe pour l'un de ses premiers disques sur le label Impulse ! (1961) un manifeste africain unique par son intention et son orchestration : Africa Brass. Sur la base de son nouveau quartet qui allait changer radicalement le son du jazz à venir, et que l'on ne nommera plus que sous le vocable de "Classic Quartet ${ }^{17}$, Coltrane ajoute une section conséquente d'instruments à vents, qui s'apparente plus à un orchestre à vents ou à une fanfare qu'au traditionnel big band de jazz. Il confie à son ami et alter ego saxophoniste Eric Dolphy le soin d'écrire les arrangements, qui sont en fait une parfaite adaptation du jeu modal et intense du pianiste McCoy Tyner. Autre particularité pour le moins rare à l'époque, Coltrane invite deux contrebassistes à jouer ensemble sur l'album, selon un mode de jeux qui semble souligner l'aspect incantatoire de ses compositions, et qu'il expérimentera à de nombreuses reprises par la suite. La musique met l'accent sur le fort potentiel expressionniste des cuivres et vents du brass band, tout en offrant au batteur Elvin Jones la possibilité de démontrer la vigueur remarquable de son jeu révolutionnaire. Pour toutes ces raisons esthétiques et musicales, Africa Brass est un album d'une modernité remarquable, mais qui semble aussi, pour une filiation qui sera significative dans le cadre de notre étude, exploiter les normes et les trouvailles de l'orchestre de Duke Ellington, particulièrement celui de sa période la plus expressionniste, celle du style jungle que l'on peut résumer à la période du Cotton Club jusqu'aux années 1940.

$\mathrm{Vu}$ à l'époque comme un joueur taiseux, virtuose, un «jeune homme en colère » au verbe musical incroyable mais jugé peut-être un peu froid ou au contraire sommaire, Coltrane semble avec cet album donner une intention plus ambitieuse à son propos, comme un ancrage dans les racines putatives les plus anciennes de la culture afro-américaine mais aussi dans celles du jazz le plus historique. Le morceau «Africa» sonne, par son titre et par son écoute, comme un véritable manifeste de l'africanité propre à l'art coltranien. John Coltrane a toujours été particulièrement attentif à la culture africaine, dans une posture qui relève autant de sa curiosité naturelle que d'une quête des origines nécessaire. "Dahomey Dance », « Kulu Se Mama »,

17. Elvin Jones à la batterie, McCoy Tyner au piano, Reggie Workman puis, surtout, Jimmy Garrison à la contrebasse. 
« Ogunde », «Dakar» sont autant de moments de la discographie de Coltrane qui démontrent son intérêt pour le continent noir. «Tunji » est le morceau qui rend hommage à son ami Olatunji, l'un des premiers percussionnistes africains à obtenir le succès aux États-Unis, et qui illustre la réalité de sa volonté d'approcher de plus près, concrètement, la culture musicale africaine. «Africa » va au-delà. Ce morceau donne en partie le titre à l'album, et marque l'œuvre sous le sceau d'une fierté diasporique affichée et volontaire. La musique donne alors à entendre un festival de sonorités expressionnistes, d'interactions de timbre et de rythme et d'intentions libertaires contrôlées, avec une étonnante et dynamique superposition modale (les basses en mi, faisant vibrer la corde la plus grave de l'instrument, et un ré mineur dont le reste de l'orchestre s'empare). Mais au-delà de ce morceau, Africa Brass reste un album trop universaliste pour être revendiqué comme une représentation totalement afrocentriste. La présence de «Greensleeves » dans ce projet africain laisserait songeur n'importe quel afrocentriste radical. Considéré comme un hymne officieux de la culture celte, on peut difficilement faire plus européen que cette chanson. Elle a pourtant inspiré des artistes de tous horizons, de la pop à la musique baroque, et a subi toutes sortes de transformations, de Jacques Brel («Amsterdam ») aux chants de Noël («What Child is This ? )). La présence de cette mélodie dans le répertoire coltranien ne doit pourtant rien au hasard, au-delà de l'évidente nécessité pour Coltrane de renouveler le succès de My Favorite Things (publié en 1960) avec cette valse celte modale (Imbert 2014). Elle affiche surtout une volonté de sa part d'intégrer une quête des racines dans une démarche holistique plus globale, qui voit dans la musique modale un outil réactualisé d'universalisme. Ainsi, John Coltrane s'exprimant sur Ravi Shankar et l'importance de la modalité :

« Il y a beaucoup de musique modale qui est jouée chaque jour de par le monde. Elle est particulièrement évidente en Afrique mais, que vous vous tourniez vers l'Espagne ou l'Écosse, vers l'Inde ou la Chine, c'est encore elle que vous retrouvez à chaque instant. Si vous voulez bien regarder au-delà des différences de styles, vous constatez qu'il existe une base commune. Ça c'est très important. Certes, la musique populaire de l'Angleterre n'est pas celle de l'Amérique du Sud, mais ôtez leurs caractéristiques purement ethniques, c'est à dire leur aspect folklorique et vous vous trouverez en présence d'une même sonorité pentatonique, de structures modales comparables. C'est cet aspect universel de la musique qui m'intéresse et m'attire, c'est vers lui que je veux aller»(Coltrane \& Delorme 2011 : 44-45).

Ainsi, Africa Brass n'est pas que la manifestation d'une filiation africaine revendiquée, il est aussi et surtout l'affirmation d'une vision universelle de la musique, avec l'Afrique comme centre vital et essentiel. Cela s'exprime également avec «Song of the Underground Railroad», que Coltrane interprète à un tempo très rapide pour cet album. Ce morceau est une adaptation du célèbre «Follow The Drinkin' Gourd », un spiritual que la culture populaire a célébré comme un chant secret de l'Underground 
Railroad, permettant de donner la bonne direction aux esclaves fugitifs par un langage codé. Si les chercheurs actuels demeurent sceptiques sur la réalité de ce langage secret et codé pour les chants comme pour les quilts (Bresler 2008; Kelley 2008), il n’en reste pas moins que ce légendaire démontre la présence dans la culture populaire d'une "pensée secrète » qui s'exprime, pour lutter contre l'oppression, sous plusieurs degrés de lecture et de compréhension. On peut voir, comme Lewis Porter (2007), dans « Greensleeves » et «Song of Underground Railroad », l'intérêt de Coltrane pour une folk music universelle. Mais on peut, pour ce dernier chant, l'interpréter également comme un hommage manifeste pour son grand-père, figure du méthodisme noir militant de Caroline du Nord. Nous revenons ainsi à ce lien qui semble unir ce protestantisme politique noir ancestral, associé aux sociétés fraternelles maçonniques, et la connaissance profonde qu'ont manifesté les artistes de jazz pour cette histoire. Coltrane renouvellera l'hommage en réadaptant une version rare et mineure du célèbre spiritual « Nobody Knows the Trouble I've Seen » et en l'intitulant «Spiritual» (Porter 2007). Africa Brass, comme l'ensemble de l'œuvre de John Coltrane, n'est pas réductible à une lecture essentialiste et échappe à toute récupération racialiste trop intempestive. Il n'en reste pas moins la démonstration évidente d'une quête d'identité et de racines d'un génie parfaitement au fait de la culture et des interrogations de son peuple.

\section{«Egyptian Fantasy » : jazz et afrocentrisme}

Si, à l'instar de John Coltrane, le jazzman n'est pas un afrocentriste revendiquant une tabula rasa de l'histoire humaine et occidentale ${ }^{18}$, il est tout de même un acteur majeur d'une vision de la place de l'Afro-Américain dans la société, qui s'exprime dans une fierté noire qui revendique plus ou moins son nom selon les époques.

Dès le XIX ${ }^{\mathrm{e}}$ siècle, au moment où le protestantisme et la franc-maçonnerie noire, fers de lance d'une petite bourgeoisie noire militante, commencent à revendiquer une primauté africaine sur les mythes et croyances de l'histoire, la culture populaire met en scène une manière d'être Noir pour l'homme de la rue et le prolétariat américain. Nous savons, avec William Lhamon (2008), que le Blackface n'est pas que la manifestation raciste du Blanc qui se grime en Jim Crow pour mieux ridiculiser le Noir. Au contraire, c'est la récupération par l'élite et la bourgeoisie de l'époque qui transforme cet art en représentation nauséabonde propre à justifier la ségrégation, alors qu'il était au départ une manière de dépasser les problèmes identitaires,

18. Même si certains musiciens seront très clairs dans leur revendication, comme Pharoah Sanders (dont le prénom est en soit un manifeste !) avec « Upper Egypt and Lower Egypt », et plus tard "Our Roots Began in Africa », Joe Henderson avec sa composition de 1969 « Afro-Centric » (dans l'album Power to the People) ou plus globalement avec l'afrofuturisme égyptomaniaque de Sun Ra. 
d'échapper à l'oppression sociale que tout prolétaire, blanc ou noir, pouvait subir. Le Blackface, et ensuite toute sa descendance musicale populaire et itinérante, les minstrels shows, les coon songs, traveling shows, vaudeville, plus tard le ragtime, le jazz, le jive, voire le rap, auront pour mérite de jouer des stéréotypes et de proposer, en seconde lecture, une interprétation de ceux-ci bien plus habile que les clichés pourraient le laisser croire. C'est le règne du signifying démontré par Henry Louis Gates ${ }^{19}$. L'artiste noir ou grimé joue et surjoue ce qu'attend le public blanc, venu profiter d'un spectacle exotique ou burlesque qui lui semble convenir à sa vision raciste des choses. Dans le même temps, l'artiste et l'homme noir de la rue se moquent de ces clichés et se les réapproprient pour mieux signifier le scandale de sa situation, au nez et à la barbe du pouvoir et du contrôle. Dans ce contexte, naît un double jeu de la terminologie africaine, qui sert autant le racisme patenté du public blanc qu'une fierté noire plus ou moins manifeste. Les termes «Abyssinia », «Ethiopia» «Dahomey » ou plus péjorativement «Hottentot», voire «Zulu» remplacent peu à peu au long du $\mathrm{XIX}^{\mathrm{e}}$ siècle le terme «Africa » qui semblait convenir aux maçons de Prince Hall, nous l'avons vu, et accompagnent toute la terminologie ségrégationniste qui affectionne officiellement les mots colored ou negro. Les « Ethiopian Minstrels » sont des spectacles qui parodient la communauté noire du Sud pour la ridiculiser et en faire un enjeu de spectacle burlesque.

Pourtant, le mot Ethiopia est parfaitement connu des artistes et intellectuels noirs comme se référant à la plus haute idée de civilisation africaine. Dans leurs deux remarquables études sur les racines de la musique populaire noire qui consacrent l'importance des troupes itinérantes de vaudeville, de ragtime, de coon song et minstrels dans l'édification d'une musique noire, Lynn Abbott et Doug Seroff (2007) relèvent un nombre important de ces groupes et de ces spectacles qui prennent pour titres une haute filiation africaine. Le célèbre duo Walker \& Williams ${ }^{20}$ concrétiseront 1'un de leur spectacle les plus ambitieux, «Abyssinia », en 1905. Le spectacle offre

19. Le concept du signifying monkey théorisé par H. L. GATES (1988) démontre la nature du double langage utilisé par les auteurs afro-américains, comme par les esclaves et leurs descendants, pour se jouer de l'oppression intellectuelle et policière. Du Blackface jusqu'au rap, en passant par les œuvres de Zora Neale Hurston, Ishmael Reed et Ralph Ellison, c'est l'ensemble de la production populaire et littéraire afro-américaine qui peut se lire sous l'aune de ce concept. Un concept qui, d'une certaine manière, conserve une pertinence importante pour comprendre l'histoire de la maçonnerie noire américaine, entre plagiats et emprunts à une institution blanche jusqu'à l'affirmation d'une identité symbolique spécifiquement noire.

20. Notons au passage que George Walker et Bert Williams seront initiés à la Lodge Waverley no 597 à Edinburgh, Écosse, en 1904. Ils deviendront ainsi des francsmaçons noirs initiés par une loge reconnue par les loges blanches américaines, même si, à l'évidence, les Écossais n'avaient pas les mêmes préjugés raciaux que leurs frères américains. À sa mort en 1922, Bert Williams recevra tous les honneurs maçonniques célébrés par la Ste Cecile Lodge de New York, à la demande de la Grande Loge d'Écosse. Chose rarissime à l'époque, un frère noir est célébré par une loge mainstream blanche. 
au public blanc un festival d'exotisme et de clichés tel qu'il l'apprécie et l'attend. Mais comme toutes ces productions aux patronymes africains, il diffuse subrepticement le nouvel art afro-américain appelé au plus grand succès, et une certaine estime de la valeur intrinsèquement africaine de cette production.

Dans leurs ouvrages où les productions et troupes "éthiopiennes", «abyssiniennes » ou «Dahomey » sont légions de la fin du XIX ${ }^{\mathrm{e}}$ siècle au début $\mathrm{Xx}^{\mathrm{e}}$, Doug Seroff et Lynn Abbott notent à nouveau l'importance des loges fraternelles, en premier lieu maçonnes, mais aussi Knigth of Pythias et Odd Fellows, dans l'élaboration des tournées et des événements. Organisations fraternelles non spécifiquement maçonniques, les Odd Fellows et les Pythias ont le mérite de recruter dans un tissu social un peu plus prolétaire que les maçons, et ainsi de diffuser ce sens du langage symbolique et mythologique à d'autres sphères de la société afro-américaine. Ma Rainey et toute sa troupe sont initiées à une loge féminine affiliée aux Pythias, durant une tournée (ibid.). L'initiation maçonnique ou fraternelle représente aussi pour ces artistes itinérants une forme d'assurance tout risque, du moins elle apporte la quasi certitude de trouver de l'aide et du soutien durant les longs mois de tournée dans des villes inconnues, à l'instar du musicien voyageur du XVIII ${ }^{\mathrm{e}}$ siècle, au temps de Mozart. Elle contribue également à diffuser et asseoir un langage symbolique et initiatique qui interprète les mythes et les écrits sacrés, pourtant européens, dans un sens largement afrocentré. Ainsi, les termes «Ethiopia », «Abyssinia », «Dahomey» ou «Egypt», s'ils assurent au public blanc une garantie d'exotisme bon marché et de sauvagerie caricaturale, représentent pour ces artistes et les initiés une autre mythologie, dont ils sont fiers et qu'ils peuvent revendiquer, même sous la forme d'un double langage plus ou moins codé. Une mythologie qui se pérennise plus tard dans le jazz, comme avec le magnifique «Egyptian Fantasy » de Sydney Bechet.

Même le blues rural n'échappe pas à cette dualité. Au début de l'histoire du blues, de par sa nature individualiste, avec des paroles avant tout personnelles, et son impact exclusivement destiné à la communauté noire, le blues n'a pas vocation à porter une voix contestataire au-delà du cercle communautaire. Mais en tant que tel, il est en quelque sorte protégé et moins surveillé que les artistes itinérants, et le bluesman rural peut en ce sens se sentir un peu plus libre de sa parole. Dès les années 1920, alors que le blues commence à connaître un relatif succès discographique, il est en quelque sorte plus assujetti à la censure et à la surveillance du pouvoir. Mais de nombreux musiciens témoignent dans leurs œuvres de la tradition de contestation sociale et politique que le blues représentait dans le cercle plus restreint de la cellule familiale ou villageoise (Jones 1997; Springer 1999), et ont ainsi porté cette voix au-delà de ce cercle, avec ce même sens du langage codé. Big Bill Bronzy avec son fameux «Black, Brown and White », Leadbelly et son "Bourgeois Blues », J. B. Lenoir et son «Vietnam Blues », Tommy Mclennan et son «Bottle It Up and Go », Josh White 
durant toute sa carrière, sont quelques exemples parmi tant d'autres d'un chant critique qui remet en question la place du Noir dans la société américaine, avec d'autres voix qui viennent du gospel et du spiritual, comme les prêches enflammés du révérend J. M. Gates ou les récitals de Paul Robeson. Démontrant au passage que la maçonnerie noire ne recrutait pas que dans les rangs de la bourgeoisie noire urbaine, de nombreux bluesmen font partie de l'ordre : Fred McDowell, Memphis Slim, Sammy Price, Howlin' Wolff, T-Bone Walker, Champion Jack Dupree, Son House, ce dernier donnant une vision toute personnelle de la Bible et de saint Jean de Patmos avec son «St John the Revelator». Ainsi, même dans le secteur plus isolé (pourrait-on croire) de la ruralité musicale américaine, l'initiation maçonnique représente le même facteur d'émancipation, de solidarité et d'interprétation mythologique. Aucun secteur de la culture noire américaine n'échappe en fait, de prêt ou de loin, à l'influence de cette culture initiatique et fraternelle.

Mais nous l'avons vu, l'âge d'or de cette conjonction maçonnique avec la musique afro-américaine correspond également à l'âge d'or des grands orchestres de jazz, la Swing Era ou Big Bands Era. Les quatre plus importants chefs d'orchestre noirs américains des plus célèbres big bands de l'époque sont maçons: Cab Calloway, Count Basie, Duke Ellington ( $32^{\mathrm{e}}$ degré du rite écossais ancien et accepté) et Lionel Hampton (33 ${ }^{\mathrm{e}}$ degré, le plus important $)^{21}$. Plus particulièrement, ce qui fut appelé le style «jungle » pourrait être le climax d'une véritable révélation de cette culture de fierté noire et de pré-afrocentrisme qui sourd depuis longtemps dans cette culture initiatique. Duke Ellington en est le fer de lance, et le plus évident dans la revendication d'une beauté noire et d'une mythologie afro-américaine qui s'expose enfin. « Black Beauty», «Black and Tan Fantasy », « Creole Love Call », «Ko-Ko », « Echoes of the Jungle », « The Mooche » « Creole Rhapsody » sont les hymnes expressionnistes, qui parodient autant une jungle fantasmée qu'urbaine, d'une valorisation de la beauté noire, en pleine Harlem Renaissance. Toujours joué pour un public exclusivement blanc au Cotton Club, le répertoire de Duke Ellington ne cache plus pour autant, comme auparavant, son ambition sociale, spirituelle et politique. Enregistrant avec Rex Stewart en 1941 un « Menelik The Lion of Judah », Duke Ellington et ses musiciens ne cachent pas non plus leur connaissance d'un des plus importants mythes africanisés par les maçons de Prince Hall, le roi légendaire d'Éthiopie, fils de Salomon et de la Reine de Saba. En 1943, Duke Ellington écrit le manifeste par excellence de la fierté noire avec son «Black, Brown and Beige », qu'il crée dans le temple new-yorkais de la musique classique, le Carnegie Hall. Sous une forme de suite symphonique qui revendique un égalitarisme formel avec les grandes œuvres classiques,

21. Autre grand chef d'orchestre de l'époque, Jimmie Lunceford nourrit un débat sur son appartenance maçonnique, non avérée. Une loge actuelle de Prince Hall de Détroit, porte pourtant son nom. Elle est constituée essentiellement de musiciens. 
Ellington expose en plusieurs mouvements une histoire et une utopie du peuple afro-américain, parmi lesquels «Emancipation Celebration, Work Song », et «West Indians Dance » qui rend hommage aux combattants haïtiens venus au secours de la révolution américaine durant le siège de Savannah. "Come Sunday » quant à lui affirme l'importance du spirituel dans cette représentation. Après la guerre, de nombreuses œuvres ellingtoniennes continueront leur célébration de l'héritage et de la richesse africaine : «Liberian Suite», «La plus Belle Africaine», "Springtime in Africa », «Fleurettes Africaines », «Pyramid, Congo Square », «Zanzibar ». Duke Ellington sera même un des invités de marque du premier Festival mondial des arts nègres de Dakar, organisé par Senghor et Alioune Diop. Plus particulièrement, deux œuvres tardives retiennent notre attention: «The Afro-Eurasian Eclipse » (1971) et «Three Black Kings (Les Trois Rois Noirs)»(1974). La première suite est, de l'aveu même de Duke Ellington dans le livret de l'album, inspirée d'une réflexion du sociologue Marshall McLuhan comme quoi le monde s'orientalise. Introduisant l'album d'un long monologue de sa voix profonde, il conclut qu'après des années à parcourir le monde, il a bien constaté que la théorie de McLuhan était vraie. La suite célèbre une forme de «village global » où l'Afrique (titre $\mathrm{du}$ troisième mouvement) tient une place de choix. Cette vision orientale d'une globalisation en mouvement n'est pas nouvelle au sein de la société américaine. Ni même dans l'histoire particulière de l'islamisation au sein de la communauté afro-américaine, qui commence au début du $\mathrm{Xx}^{\mathrm{e}}$ siècle avec la vision hétérodoxe et atypique de Noble Drew Ali. La création de son Moorish Science Temple, profondément marqué par la pratique ésotérique et maçonnique, revendique la séparation des races humaines entre Maures d'origine orientale (les Noirs) et les Blancs caucasiens, entre un Orient bénéfique et un Occident diabolique ${ }^{22}$. Duke Ellington, pétri de cette afromythologie maçonnique, mais aussi d'un humanisme qui dépasse largement les essentialismes racialistes, donne à son «éclipse afro-eurasienne » une tonalité bien connue parmi les nombreux initiés de la culture afroaméricaine, tout en lui apportant la largeur de vue de l'universaliste qu'il est. «Three Black Kings » est quant à lui une commande du Dance Theater of Harlem, dont Duke Ellington ne verra pas la création, survenant après sa disparition en 1974. Les «Trois Rois Noirs » sont Balthazar, l'un des trois rois mages, le roi Salomon et Martin Luther King. La présence du roi Salomon peut surprendre. Mais Salomon, par ailleurs figure fondatrice de la mythologie maçonnique par la construction du Temple, est fils de David et de Beersheba, dont une tradition rappelle qu'elle serait noire, en tant que descendante de Ham. Ainsi, l'œuvre opère une lignée mythique entre les temps anciens et un présent glorifié par le couronnement du pasteur King,

22. Pour une étude complète de l'islam afro-américain, dont le Moorish Science Temple, voir TURNER (2003). 
selon une habitude bien connue du grand Duke qui consistait déjà dès Prince Hall à s'affilier aux plus nobles et plus anciennes filiations, bibliques et maçonniques.

\section{«Great Black Music : Ancient to The Future»}

Après la Seconde Guerre mondiale, les effectifs de la franc-maçonnerie de Prince Hall s'écroulent, et le nombre de musiciens qui y appartiennent également. La guerre aura eu pour fonction de produire un éveil des consciences qui exige une autre forme de lutte, plus active, plus radicale, plus impliquée. De plus, avec l'émergence du be bop, un phénomène nouveau vient changer radicalement le paysage spirituel du monde culturel afro-américain. Un nombre important de musiciens liés à cette nouvelle musique se convertit à l'islam, en très grande majorité ahmadyiste (Imbert 2014). Cette forme d'islam hétérodoxe apporte une fierté nouvelle, un souffle novateur dans l'affichage d'une dignité et d'un combat proprement afro-américains. Le batteur Art Blakey explique ainsi son choix de se convertir, suite à une altercation avec un officier de police à Albany, Géorgie :

«Après cette expérience, j'ai commencé à chercher une philosophie, un mode de vie meilleur. Je savais que la maçonnerie ne me l'apporterait pas, et que le christianisme avait depuis longtemps échoué à le faire » (Kelley 2009: 126, ma traduction).

Même si nous savons, avec Pauline Guedj (2003), que nous ne devons pas confondre l'islam afro-américain et l'afrocentrisme intellectuel, qui sont même antagonistes dans leurs propos, leurs arguments, et leurs buts, il ne faut pas négliger l'importance de cette tradition islamique dans l'évolution des mentalités vis-à-vis des mythes afrocentristes et de la fierté noire. De nombreux musiciens convertis, comme Art Blakey, McCoy Tyner, Yusef Lateef, Ahmad Jamal, Kenny Clarke (musulman et maçon) continueront l'œuvre de leurs prédécesseurs en la renouvelant par leur nouvelle discipline spirituelle. Citons aussi parallèlement l'importance des Shriners, un organisme paramaçonnique de hauts grades qui travaille avant tout pour les œuvres caritatives, qui aura contribué depuis la fin du XIX ${ }^{\mathrm{e}}$ siècle à diffuser dans la communauté afro-américaine un imaginaire à la fois islamisant, orientalisant, et africanisant, et dont de nombreux jazzmen ont fait partie. Ainsi, depuis le be bop jusqu'au hard bop, alors que les musiciens appartiennent de moins en moins à la maçonnerie, le mythe afrocentrique et les formes de revendications politiques et spirituelles les plus radicales et les plus évidentes sont parfaitement assumés par les musiciens de la nouvelle école, depuis Charles Mingus, en passant par Max Roach, Randy Weston, Archie Shepp, ou Joe Henderson et son «Afro-Centric» de l'album Power to the People de 1969. 
Avec le free jazz, nous arrivons à la quintessence de ce paradoxe historique qui voit le nombre de musiciens maçons s'effondrer, mais les références à sa mythologie, sa symbolique et son histoire exploser dans les titres, les iconographies et les liner notes des albums. Il n'y a plus de musiciens frères, mais la fraternité est recyclée, ingurgitée, transformée, et sa mythologie afrocentrique largement diffusée par les musiciens d'avantgarde, dans un souci de syncrétisme novateur. Wayne Shorter intitule son album le plus spirituel The All Seeing Eye (L'œil qui voit tout), Albert Ayler prend la cornemuse pour son «Masonic Inborn », Muhal Richard Abrams pense en Levels and Degrees of Light, Steve Reid raconte son Odyssey of Oblong Square, William Hooker affiche des symboles peu équivoques. George Russel quant à lui baptise ses modes novateurs de noms bien antiques. Et jamais autant de pyramides, de références égyptiennes antiques, de symboles africains n'auront autant illustré les pochettes d'albums, en jazz, mais aussi largement dans la production funk et soul de l'époque. Le temps n'est plus au codage d'une symbolique réservée aux seuls initiés, voici venu le temps de révéler la vérité, dans toutes ses formes. Pourtant le culte du secret n'a pas encore disparu, comme en témoigne Steve Coleman lorsqu'il raconte son « initiation » aux mystères ésotériques, et la nature particulière de cette transmission, évoquant un livre dont lui avait fait cadeau Anthony Braxton :

«C'est la première fois que j'entendais parler des Mystères de l'Égypte ancienne, une direction que j'ai finalement empruntée depuis. Mais il ne voulait pas m'en parler, alors je suis devenu très curieux sur le sujet. Braxton en avait entendu parler par Muhal (Richard Abrams NdT) [...]. Le fait de mélanger des principes anciens avec des nouvelles technologies me vient de ces gens-là et cela se pratiquait déjà avec Sun Ra, John Coltrane, Cecil Taylor [...]. Lorsque vous lisez des articles sur eux, ils ne l'évoquent jamais. J'en parle probablement plus que la plupart de ces musiciens. Et après la sortie de mon disque, Muhal m'appela pour me demander d'être prudent. Je ne tiens pas trop à en parler, mais il doit sûrement avoir raison car il en sait davantage que moi.

$\mathrm{Q}$ : Mais qu'est ce qui peut être si dangereux ?

$\mathrm{R}$ : Nous manipulons des informations qui peuvent être utilisées à des fins beaucoup plus sombres. [...] Le troisième Reich en est l'exemple le plus récent [...] » (Bergeras \& Dutilh 2001: 15).

L'AACM ${ }^{23}$ et toute cette École de Chicago peuvent alors se revendiquer comme les gardiens du temple, d'un secret encore trop important pour être divulgué. Pourtant un autre illustre musicien de Chicago n'aura pas ces scrupules. Sun Ra, dans sa carrière magnifique qui le fera débuter à l'époque du swing pour aller vers les grandes expériences sonores synthétiques et électroniques, refondera des pans entiers de la mythologie ésotérique afroaméricaine, de l'égyptologie et de l'astronomie pour créer son propre culte

23. Association for the Advancement of Creative musicians, association créée en 1965 à Chicago, sous la houlette du pianiste et compositeur Muhal Richard Abrams. 
musical et mystique, débordant d'un afro-futurisme révolutionnaire. Le peuple noir est selon Sun Ra emprisonné sur Terre par les forces du mal, et doit rejoindre sa patrie d'origine, Saturne. Ainsi, le peuple noir est le seul et véritable peuple élu, héritier des visiteurs qui ont initié la civilisation égyptienne, et la force de sa musique permettra de donner l'énergie nécessaire pour rejoindre la planète originelle. On sait avec John Szwed (1988) que Sun Ra, dans sa jeunesse à Birmingham, fréquenta assidument la bibliothèque maçonnique du temple de Prince Hall, moins ségréguée que la bibliothèque municipale. C'est évidemment dans ce contexte qu'il découvrira pour la première fois l'Égypte ancienne et la mythologie éthiopienne.

La boucle est bouclée, en quelque sorte. Et ainsi, elle nous invite à observer l'histoire de la musique afro-américaine de manière rétrospective, pour mieux apprécier l'importance du fait maçonnique dans l'élaboration d'une pensée mythologique afro-américaine et afrocentrée qui inspira les artistes dans leur ensemble. En regardant depuis Sun Ra jusqu' au Blackface et aux negro spirituals, nous découvrons non pas une succession de révolutions esthétiques antagonistes mais un véritable fil conducteur qui s'exprime d'abord en secret, qui avance masqué, et prend ensuite toute son ampleur avec l'avant-garde des années 1960, jusque dans la méthode numérologique actuelle d'un Steve Coleman, totalement redevable d'une connaissance profonde de l'Égypte, des nombres et de l'ésotérisme antique. Martin Delany aurait presque pu voir chez lui ou chez Sun Ra des successeurs.

Mumbo Jumbo : conséquences esthétiques d'une mythologie ancestrale et contemporaine

Ce fil conducteur et cette conjonction entre l'art du jazz et cet ésotérisme mythologique afro-américain est parfaitement mis en scène par Ishmael Reed (1998) dans son roman Mumbo Jumbo, polar ésotérique et truculent qui s'approprie cette dualité initiatique, entre secret et affichage militant. L'histoire repose sur la lutte immémoriale entre l'Ordre de la Fleur de Muraille (The Wallflower Order), représentant la Voie atoniste - les disciples d'Aton, premier monothéisme de l'histoire - et Djeuze Grou (Jes Grew), émanation sacrée de la véritable religion africaine, originaire des cultes polythéistes noirs d'Osiris qui sacralisent le corps, la danse et l'amour. $\mathrm{Au}$ début de l'histoire, le Djeuze Grou revient à travers le monde par le biais du jazz, qui met en transe de plus en plus de monde, tel un virus bénéfique qui exhorte les gens au bonheur de la danse et de l'amour. L'Ordre de la Fleur de Muraille s'allie avec les Templiers et d'autres ordres initiatiques blancs et occidentaux (dont la maçonnerie) pour mener la lutte finale. Mais à la fin du roman, ce sont des francs-maçons noirs qui viennent finalement au secours des adeptes voodoo de «Djeuze Grou». Chacun, maçons et voodoo, recherchent le Livre sacré de Thot, disciple d'Osiris, qui vitalise la force de «Djeuze Grou» et prouve les origines africaines 
de la franc-maçonnerie, réceptacle secret des enseignements et des mystères antiques de l'Afrique ancestrale dévoyés par la franc-maçonnerie «caucasienne », blanche. Tour à tour, la franc-maçonnerie est décrite par Reed comme garante de l'ordre oppresseur et comme protectrice des secrets africains de la Tradition. Papa LaBas, personnage central du roman, protecteur $\mathrm{du}$ «Djeuze Grou » et sorcier voodoo, reconnaît comme initié le Grand Maître de la première Grande Loge Boyer de Prince Hall, Buddy Jackson, protecteur du Livre sacré, par «l'ancienne poignée de main africaine: la vulve enserrant le phallus » (ibid. : 250), soit en somme l'attouchement maçonnique! Ce dernier décrit ainsi les mesures de protection langagière secrètes et traditionnelles que eux, maçons noirs de Prince Hall, réactualisèrent pour éviter les attaques des «frères » blancs, et protéger leur savoir initiatique ancestral :

« Nous avions inventé nos propres textes, nous avions notre argot dont leurs érudits se gaussaient. Tout cela est pourtant bien vivant, semble faire partie de nous, ne manque pas d'apparaître dans nos fêtes et cérémonies. La Charte des Filles de l'Étoile d'Orient (Eastern Star, NDR) est, comme vous le savez, rédigée dans cette langue du mystère qu'il qualifie d'argot ou de dialecte. Je me souviens que l'un de nos frères nous révéla une nuit que le rituel de leur messe reprend également celui d'une cérémonie de l'ancienne Égypte noire » (ibid. : 252).

Cette histoire méconnue de la franc-maçonnerie noire, ici fantasmée par Ishmael Reed, est une part importante et pourtant délaissée de l'Atlantique noir cher à Paul Gilroy. Institution européenne totalement réinventée par les Noirs de Prince Hall tout en préservant intégralement l'intégrité des rituels d'origine, cette maçonnerie illustre d'une manière inédite les échanges mythologiques et symboliques qui ont contribué à l'édification d'une identité afro-américaine spécifique. La manière dont les musiciens de jazz — dont on doit rappeler ce qu'ils représentent d'essentiel dans ce dialogue transatlantique symbolique, et qui se sont d'abord rendus redevables de cette tradition maçonnique pour ensuite exprimer au grand jour une pensée et une fierté afro-américaine inédite - se sont emparés de cette tradition maçonnique est la manifestation du rôle que ces acteurs culturels, spirituels, politiques et intellectuels ont eu sur l'histoire américaine.

Il ne s'agit donc pas ici de tenter de démontrer que les jazzmen ont porté intellectuellement et politiquement l'idée afrocentrique dans sa globalité lors de leurs créations et de leurs manifestations spirituelles. Mais nous commençons à entrevoir ce lien insoupçonné qui voit artistes et racines spirituelles et initiatiques converger vers une vision originale de la place de l'Afrique dans la société qui, dès le $\mathrm{XIX}^{\mathrm{e}}$ siècle, semble clairement s'identifier à une relecture conceptuelle et spéculative de l'Antiquité égyptienne, et des civilisations ancestrales de l'Afrique, Éthiopie en tête. Certes, c'est d'un imaginaire fantasmatique qu'il s'agit, entre mythologie plurielle et interprétation subjective, sans véritable fondement historique. Mais là où les intellectuels afrocentristes modernes n'auront évidemment jamais totalement évacué la 
question de la scientificité de leur théorie, les jazzmen auront fait de cet imaginaire afrocentriste un objet culturel et esthétique universel, et les francs-maçons une mythologie parfaitement applicable à l'expérience afroaméricaine. Plus encore, cette conjonction entre l'artiste, le franc-maçon et l'idée afrocentriste démontre que jazz et société initiatique afro-américaine n'auront pas été à la traîne des idées novatrices de leur époque. Le jazzman, influencé par le contexte spirituel et politique de sa culture initiatique, sera finalement un précurseur sans étiquette des idées qui allaient remettre en question plusieurs siècles d'histoire «officielle » et de vision du monde, s'offrant le luxe, c'est l'apanage de l'artiste, de ne pas tomber dans les travers des débats polémiques de l'afrocentrisme intellectuel.

Musicien, chercheur affilié au LAHIC, Charenton-le-Pont.

\section{BIBLIOGR APHIE}

Аввотt, L. \& Seroff, D.

2002 «The Life and Death of Pioneer Bluesman Butler "String Beans" May », Tributaries, Journal of the Alabama Folklife Association: 9-48.

2007 Ragged but Right : Black Traveling Shows, Coon Songs, and the Dark Pathway to Blues and Jazz, Jackson, University Press of Mississippi.

ARMSTRONG, L.

2006 Ma vie à la Nouvelle Orléans, traduit par Françoise Thibaut, Paris, Coda éditions.

AsANTE, M. K.

1980 Afrocentricity, the Theory of Social Change, Buffalo, N.Y., Amulefi Pub.

AsukiLe, T.

1999 «The All-Embracing Black Nationalist Theories of David Walker's Appeal », The Black Scholar, 29 (4) : 16-24.

Bergeras, G. \& Dutilh, A.

2001 «Steve Coleman cite ses sources », Jazzman, 71, juillet/août.

BERNAL, M.

1987 Black Athena : The Afroasiatic Roots of Classical Civilization, New Brunswick, N. J. Rutgers University Press.

Béthune, C.

2008 Le jazz et l'Occident. Culture afro-américaine et philosophie, Paris, Éditions Klincksieck. 
BORELlO, J.-M.

2007 «Blues et Franc-Maçonnerie », Soul Bag, 155 : 12-15.

BRESLER, J.

2008 «Follow the Drinking Gourd : A Cultural History », $<$ http://www.followthedrinkinggourd.org/>.

BROTHERS, T.

2007 Louis Armstrong's New Orleans, New York, W. W. Norton \& Company, Inc.

Chivallon, C.

2004 La diaspora noire des Amériques: expériences et théories à partir de la Caraïbe, Paris, Éditions du CNRS.

Coltrane, J. \& Delorme, M.

2011 Je pars d'un point et je vais le plus loin possible, Paris, Éditions de l'Éclat.

Cox, J.

2002 Great Black Men of Masonry, New York, Rpt Black Inprint.com.

Delany, M. R.

1852 The Origin and Objects of Ancient Freemasonry; Its Introduction into the United States and Legitimacy Among Colored Men, Pittsburgh, W. S. Haven.

1879 Principia of Ethnology: The Origin of Races and Color with an Archaeological Compendium and Egyptian Civilization from Years of Careful Examination and Enquiry, Philadelphia, Harper \& Brothers.

2003 A Documentary Reader, Édité par Robert S. Levine, Chapel Hill, University of North Carolina Press.

DiAL, H.

1983 All this Jazz about Jazz, Chigwell, Essex, England, Storyville.

Diop, C. A.

1954 Nation nègre et culture, Paris, Présence Africaine.

GATES, H. L.

1988 The Signifying Monkey: A Theory of African-American Literary Criticism, New York, Oxford University Press.

GILROY, P.

2003 L'Atlantique noir. Modernité et double conscience, Paris, Kargo.

GREMillion, Z. P.

2005 African Origins of Freemasonry, Bloomington, Authorhouse.

GuEDJ, P.

2003 «Des Afro-Asiatiques et des Africains : islam et afrocentrisme aux ÉtatsUnis », Cahiers d'Études africaines, XLIII (4), 172: 739-760.

2004 «A Nation Within Nations. Nationalisme afro-américain et réafricanisation aux États-Unis », Civilisations, $51: 23-38$.

2009 «Afrocentrismes américains », Civilisations, 58 (1) : 9-21. 
Hinks, P. P. \& Kantrowitz, S.

2013 All Men Free and Brethren; Essays on the History of African American Freemasonry, Ithaca-London, Cornell University Press.

Hinton, M. \& Berger, D. G.

1991 Bass Line, Philadelphia, Temple University Press.

Hinton, M., Berger, D. G. \& Maxson, H.

2008 Playing the Changes : Milt Hinton's Life in Stories and Photographs, Nashville, Vanderbilt University Press.

IMBERT, R.

2011 «Jazz en vies, de l'exemplarité du fait spirituel et maçonnique chez les musiciens de jazz », L'Homme, 200 : 141-174.

2014 Jazz Supreme. Initiés, mystiques \& prophètes, Paris, Éditions de l'Éclat.

JAMES, G. G. M.

1954 Stolen Legacy: The Greeks Were Not the Authors of Greek Philosophy, but the People of North Africa, Commonly Called the Egyptians, New York, Philosophical Library.

Jamin, J. \& WiLliams, P.

2010 Une anthropologie du Jazz, Paris, Éditions du CNRS.

JONES, L.

1997 Le Peuple du blues, Paris, Gallimard (« Folio »).

KAHN, A.

2007 The House that Trane Built: The Story of Impulse Records, New York, W. W. Norton \& Co.

KELLEY, J.

2008 «Song, Story, or History : Resisting Claims of a Coded Message in the African American Spiritual "Follow the Drinking Gourd" », The Journal of Popular American Culture, 41 (2) : 262-280.

KeLley, R.

2009 Thelonious Monk: The Life and Times of an American Original, New York, Free Press.

LHAMON, W. T.

2008 Peaux blanches, masques noirs, Paris, Kargo.

MARQuis, D. M.

1989 Buddy Bolden, le premier musicien de jazz, Paris, Denoël.

MiLLER, F.

1971 «The Father of Black Nationalism », Civil War History, 17 (4) : 310-319. 
MoOre, K.

2008 Freemasonry, Greek Philosophy, The Prince Hall Fraternity and the Egyptian (African) World Connection, Bloomington, Authorhouse.

Moses, W. J.

1998 Afrotopia : Roots of African-American Popular History, Cambridge, Cambridge University Press.

Munammad, E.

2008 The Secrets of Freemasonry, Phoenix, Secretarius MEMPS Publications.

National Park Service

1993 New Orleans Jazz, Louisiana, New Orleans, United States Departement of the Interior.

Newman, R., Rael, P. \& Lapsansky, P.

2000 Pamphlets on Protest; An Anthology of Early African-American Protest Literature, 1790-1860, New York, Routledge.

OBEnGa, T.

1993 Origine commune de l'égyptien ancien, du copte et des langues négroafricaines modernes. Introduction à la linguistique historique africaine, Paris, L'Harmattan.

PORTER, L.

2007 John Coltrane, sa vie, sa musique, Paris, Outre Mesure.

REED, I.

1998 [1972] Mumbo Jumbo, Paris, Éditions de l'Olivier.

RÉvauger, C.

2014 Noirs et Francs-Maçons, Comment la ségrégation raciale s'est installée chez. les frères américains, Paris, Dervy.

Smith, M. G., Augier, R. \& Nettleford, R. M.

1967 «The Ras Tafari Movement in Kingston, Jamaica », Caribbean Quarterly, 13 (3) : 3-29; 13 (4) : 3-14.

SPENCER, D. W.

1999 Dread Jesus, London, SPCK Publ.

SPRINGER, R.

1999 Fonction sociale du Blues, Marseille, Parenthèses.

Stearns, M.

1956 The Story of Jazz, New York, Oxford University Press.

Szwed, J. F.

1988 Space is the Place: The Lives and Times of Sun Ra, Cambridge, Da Capo Press. 
Tobin, J. L. \& Dobard, R. G.

1999 Hidden in Plain View, the Secret Story of Quilts and Underground Railroad, New York, Doubleday.

TrAFTON, S.

2004 Egypt Land: Race and Nineteenth-Century American Egyptomania, Durham, Duke University Press.

TURNER, R.

2003 Islam in the African-American Experience, Bloomington-Indianapolis, Indiana University Press.

WALKeR, C. D. B.

2008 A Noble Figth, African American Freemasonry and the Struggle for Democracy in America, Urbana, University of Illinois Press.

WALKER, D.

1829 An Appeal in Four Articles to the Coloured Citizens of the World, Boston, David Walker.

WALKes, J. A.

1996 «Letters-about Louis Armstrong », The Masonic Philatelic Club Magazine, avril : 23 .

WILDER, C. S.

2001 In the Company of Black Men: the African Influence on African American Culture in New York City, New York, New York University Press.

\section{RÉSUMÉ}

Le saxophoniste Albert Ayler enregistre en 1969 "Masonic Inborn », une longue et intense improvisation à la cornemuse. C'est, à notre connaissance, le seul titre de I'histoire du jazz faisant ouvertement référence à la tradition maçonnique. Cette rareté ne doit pourtant pas occulter que le fait maçonnique demeure un sujet passionnant et méconnu de l'histoire du jazz. De très nombreux jazzmen d'avant-guerre ont appartenu activement à la maçonnerie noire américaine, dite de "Prince Hall », sans pour autant l'afficher dans leurs œuvres artistiques. Après la Seconde Guerre mondiale, la maçonnerie est délaissée par les musiciens au profit de mouvements jugés plus actifs politiquement. Paradoxalement, I'utilisation de symboles maçonniques - au même titre que toute une mythologie égyptienne, afrocentrique, orientale, contre-culturelle $-\mathrm{s}^{\prime}$ affiche beaucoup plus ouvertement sur les pochettes de disques, affiches, tracts de cette époque. En étudiant des personnalités telles que Duke Ellington, Sun Ra, Cab Calloway, Ayler mais aussi Martin Delany, Lewis Hayden, Prince Hall, nous découvrirons comment les sociétés initiatiques afro-américaines, dont la francmaçonnerie, ont finalement porté la gestation d'une symbolique afrocentrique primordiale. Fait essentiel, constitutif mais méconnu de l'Atlantique noir, cette symbolique s'affichera, par un phénomène d'extériorisation inédit, sur les scènes musicales américaines avant de devenir le paradigme intellectuel et politique que I'on sait. 


\section{ABSTRACT}

"Masonic Inborn": Jazz, Initiation Societies and Afrocentrism. - In 1969 the late saxophonist Albert Ayler recorded "Masonic Inborn", a long and intense improvisation on the bagpipe. As far as we know, this tune is the only one in the history of jazz that clearly mentions the masonic tradition. This rarity should not hide the fact that the masonic occurrence is a fascinating but unknown subject of history of jazz. Many pre-war jazzmen actively belonged to the Black American masonry-called Prince Hall Masonry-but without displaying it in their artistic works. After WWII, masonry is neglected by musicians in favor of some others movements considered more politically active. Paradoxically, in the same time, the use of masonic symbols_-just like Egyptian, afrocentric, Eastern, and countercultural mythologiesappears more openly on album covers, posters and leaflets. While studying such personalities as Duke Ellington, Sun Ra, Cab Calloway, Ayler but also Martin Delany, Lewis Hayden, Prince Hall, this article will analyze how African-American initiation societies-including freemasonry-carried the gestation of a primordial afrocentric symbolism. Key, constitutive but disregarded fact of The Black Atlantic, this symbolism will appear first, by an unusual externalizing phenomenon, on American musical stages before becoming the intellectual and political paradigm we know.

Mots-clés/Keywords : États-Unis, Albert Ayler, John Coltrane, Duke Ellington, afrocentrisme, éthiopianisme, franc-maçonnerie, jazz, nationalisme noir, sociétés initiatiques/United States, Albert Ayler, John Coltrane, Duke Ellington, afrocentrism, ethiopianism, freemasonry, jazz, black nationalism, initiation societies. 